\title{
دراسة المفاهيم من زاوية فلسفية
}

\section{صلاح إسماعيل*}

\section{تمهيد}

سؤال أطرحه على نفسي -ولا شك في أن غيري يطرحه كذلك- كلما رأيت خلطاً بين المعاني عند الكتاب أو المتحاورين، وهو: ما العلة في حياتنا الفكرية؟ وفي كل مرة يأتيني الجواب: العلة هي غموض الأفكار أو المفاهيم تارة، أو تحريفها تارة أخرى. ويف هذا البحث محاولة لإلقاء أضواء شارحة على هذا الجواب.

يمكن النظر إلى المفاهيم من زوايا متنوعة، كما يمكن دراستها بطرائق ومناهج متعددة، إذ يمكن دراستها من منظور لغوي أو نفسي أو فلسفي، وهلم جرا. وسأحاول النظر إلى المفاهيم من زاوية فلسفية، وبخاصة من الناحيتين الدلالية والمعرفية (الإبتمولوجية). وسأصرف النظر عن الناحية الوجودية (الأنطولوجية) التي يجسدها السؤال: هل تتمتع المفاهيم بوجود ما؟ وإذا كانت توجد فأين توجد؟

والحق أن هناك ابحاهات ومذاهب كثيرة في تبيان ماهية الفلسفة ووظيفتها. وأبرز هذه الاتحاهات في عصرنا ما يسمى "بالفلسفة التحليلية"، ويأتي في طليعة فلاسفة هذا الاتحاه مور ورسل وفتجنشتين وأوستن ورايل وغيرهم. ومهمة الفلسفة عند هؤلاء الفلاسفة توضيح المفاهيم والأفكار عن طريق تحليل العبارات التي تصاغ فيها هذه المفاهيم، وقد يكون التحليل منطقياً خالصاً أو فلسفياً أو لغوياً. ولعل من بين أهم الفوائد التي يمكن أن يجنيها الفكر الإنساني من هذا الاتحاه إلزام المشتغلين بالفكر بالتحديد الدقيق لكل ما يعرضونه من مفاهيم وأفكار. 
يتناول الجزء الأول من هذا البحث ضرورة توضيح المفاهيم، أما الجزء الثاني فيقدم تحليلاً لبنية المفهوم يميز بين العناصر الأساسية والعناصر الإضافية في هذه البنية، ويأتي الجزء الثالث ليربط توضيح المفاهيم بنظرية المعنى على أساس أن المفهوم الواضح هو الذي يحتوي على معان واضحة يمكن إدراكها بسهولة ويسر، ويستلزم هذا شرحاً لأبرز نظريات المعنى. وسيمكننا توضيح المفاهيم وشرح علاقتها بنظرية المعنى من رصد بعض الظواهر المفهومية والدلالية مثل "الحراك المفهومي" و"الاحتلال المفهومي" و"تغيير المعنى" و"تحريف

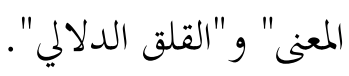

\section{توضيح المفاهيم ضرورة معرفية}

عندما ننظر إلى أي نسق معرفي لأية حضارة من الحضارات، نجد أنه يتألف على وجه التقريب من مجموعة حقول معرفية متنوعة. فهناك المعرفة الدينية، والمعرفة الميتافيزيقية، والمعرفة التجريبة، والمعرفة الرياضية والمنطقية، المعرفة الإنسانية والاجتماعية، وهلم جرا. ويتألف كل حقل من هذه الحقول بروابط ضرورية تؤدي

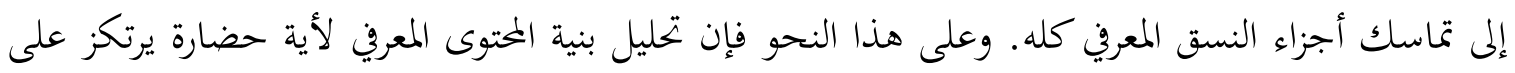
ثلاثة عناصر في غالب الأمر هي: المفاهيم، والعلاقات التي تؤلف من المفاهيم حقلاً، والعلاقات التي تشكل من الحقول نسقاً. ولو نحينا جانباً البحث في هذه العلاقات لوجدنا أن المفاهيم تحتل من البناء الفكري لأي نسق معري موقع حجر الأساس. ونظراً لأهمية المفاهيم وخطورتا في إحداث التغيير الفكري والتحول الحضاري الذي ننشده لأمتنا، فإن توضيحها يجب أن يأتي في مقدمة أولويات الفكر الإسلامي المعاصر.

ولعل السؤال الذي يطرح نفسه علينا هو: ما الذي نعنيه بالمفهوم؟ إن المفهوم بمعناه المنطقي هو

مجموعة الصفات والخصائص التي تحدد الموضوعات التي ينطبق عليها اللفظ تحديداً يكفي لتمييزها عن الموضوعات الأخرى. فمفهوم "الإنسان" بالمعنى الأوسطي، مثلا، مؤداه أنه كائن ناطق، و (ما صِدْقاته) هي محمد وأحمد وسائر أفراد الناس. ولكننا سننظر إلى المفهوم نظرة أوسع من نظرة رجل المنطق إليه، لأن المفهوم يتألف أيضاً من المعاني والمشاعر التي يستدعيها اللفظ في أذهان الناس، ولذهه لنظرة الواسعة ميزة في رأينا وهي أها تفسح المجال أمام القول بأن الغالبية العظمى من المفاهيم لا تقبل تعريفاً جامعاً مانعاً بلغة المنطق، وإنما تتسم بمرونة مطلقة لا تحدها حدود ولا تقيدها قيود، فتتسع دلالتها أحياناً وتضيق أخرى. والمفهوم في 
هذه الحالة يشبه البحر الواسع الذي يجوز لكل جيل من البشر أن ينهل منه ويبحر فيه بقدر ما تسعفه طاقته. وعلى هذا النحو فإنني أعني بالمفاهيم المعاني العقلية الكلية أو الأفكار العامة المجردة، وأبرز الأمثلة لها هي الحرية والعدالة والمساواة والحق والخير والجمال.

ومن الأهمية بمكان أن نشير إلى أنه توجد إلى جانب هذه المفاهيم الفضفاضة مفاهيم محددة الدلالة

$$
\text { إلى حد كبير، وهي مفاهيم العقيدة مثل "التوحيد" و "النبوة" و "الإيمان" و "الشرك" وغيرها. }
$$

ولكن إذا كان المفهوم يمثل معنى أو مجموعة معان بجردة، فإننا نعبر عنه برمز لغوي واحد يسمى لفظاً

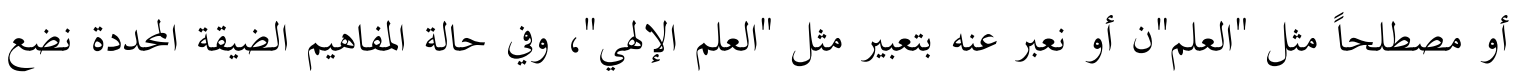
اللفظ بإزاء المعنى، وينتج ذلك مصطلحاً ينفق عليه أهل علم معين أو جماعة فكرية معينة، وقد يشيع المصطلح بمعناه المحدد وقد يظل مقصوراً على أصحابه الذين تواضعوا عليه. وليس في ذلك مشكلة، ولكن المشكلة تنشأ عندما نضع لفظاً واحداً بإزاء معان كثيرة مع غياب القرائن اللغوية التي تميز هذه المعاني. وهذا الموقف يختلف إلى حد ما عن "المشترك اللفظي" الذي يعني وضع اللفظ الواحد بإزاء معنيين متغايرين أو أكثر، لأننا في المشترك اللفظي قد نتوصل إلى تحديد المعنى المراد عن طريق القرائن اللغوية أو السياق اللغوي، وذلك مثلما يحدث مع قول البارودي:

$$
\text { فلا عين إلا وهي عين من البكا لا خد إلا للدموع به خد }
$$

فالسياق والقرائن اللفظية توضح أن "عين" الأولى هي عين الإنسان، وأن "عين" الثانية هي عين الماء، وشبه الأولى بالثانية لكثرة الماء فيهما، أما "خد" الأولى فهي جزء من الوجه على حين أن "خد" الثانية تعني الحفرة.

نقول: إننا لا نواجه مشكلة مع المفاهيم ذات المعاني المحددة سواء أكانت لغوية أو اصطلاحية، وإنما نواجه مشكلة مع المفاهيم التي تتعدد معانيها وتتسع دلالاتحا. خذ، مثلا، مفهوم "الديمقراطية" تجد اتفاقاً على أن أصله اللغوي (Demokratia) يعني حكم الشعب (ففي اللغة اليونانية نجد Demos تعني الشعب و Kratia تعني الحكم). ولكن بعد هذا الاتفاق على المعنى الاشتقاقي للكلمة سرعان ما ينشأ 
الاختلاف حول المقصود بالشعب والمراد بالحكم. ليس هذا فحسب، بل إن هذا لمفهوم -شأنه في ذلك شأن مفاهيم كثيرة- قد اتسعت دلالته بحيث يبدو وكأنه مفهوم مختلف عن المفهوم الذي ابتكره فلاسفة السياسة أول الأمر. فالديمقراطية قد تعني عند كاتب معين الحرية بمعانيها المتنوعة المتعددة: حرية التعبير، والحرية السياسية، وحرية التنقل، وهلم جرا. وهي عند كاتب آخر المساواة أمام القانون، وعند كاتب ثالث تكافؤ الفرص والتوزيع العادل للثروة. وبسبب هذه المعاني المتباينة للمفهوم الواحد يحدث الخلط في أفهام الناس خلطاً يتجلى عند المناقشة، فيتحدث الشخص عن معنى في ذهنه غير المعنى الذي يتحدث عنه شخص آخر. وهنا يأتي "توضيح" المفاهيم ليمثل ضرورة منهجية ومعرفية إذا أريد للحياة العقلية أن تزدهر في

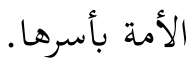

والفرق بين المفهوم الواضح والمفهوم الغامض كالفرق بين خريطة واضحة المعالم لبدل معين يصطحبها المسافر عند سفره، وورقة خط عليها طفل بجموعة خطوط لا تدل على شيء، وقيل للمسافر هذه خريطة. فانظر كيف أن المفهوم الواضح الذي ينطوي -مثل الخريطة الواضحة- على معان جلية وقيم ومبادئ واضحة يدفع إلى تقدم المعرفة عند ربطه بمفاهيم أخرى في نسق، أو يهدي إلى سواء السبيل عندما يسلك المرء على أساسه. أما المفهوم الغامض، مثل الورقة التي خط عليها الطفل خطوطاً غامضة، فإنه إذا دخل في نسق أفسد نظامه وعلاقاته مما يؤدي إلى تراجع معرفي، وإذا وجه سلوكاً لشخص أضله لأنه لا يهدي إلى شيء ولا يدل على شيء.

على أن عملية توضيح المفاهيم بالمعنى الذي نريده لها لا تقتصر على تحديد المعاني المتنوعة التي قد يدل عليها المفهوم تحديداً يهول دون وقوع اللبس والغموض بين الكتاب أو المتكلمين، وإنما تتسع هذه العملية بحيث تشمل الكشف عما تتعرض له المفاهيم في حالة تخلف الأمة حضارياً وظهور الصراع بين الحضارات وممارسة الغزو الثقافي للحضارة الغالبة على الحضارات المغلوبة، ففي هذه الحالة يتم تشويه دلالات المفاهيم الأصلية أول الأمر، ثم تفرغ شيئاً فشيئاً من محتواها، ثم يعاد ملء المفهوم بالدلالات المرادة، مثال ذلك ما حدث لمفهوم "العلم". فمفهوم العلم في خصوصيته المعرفية الإسلامية واسع الدلالة، ولكن جرت محاولة لطمس بعض هذه الدلالات أو وصفها باللغو واللاعلم، وتم قصر دلالة المفهوم على دلالة محددة هي 
العلم الطبيعي. ليس هذا فحسب، بل تم إدخال حلالات غريبة عليه مثل اعتبار العلم مناقضاً للدين. وهذه الظاهرة التي نسميها "الاحتلال المفهومي" جديرة بالدراسة والتحليل.

وهناك ظاهرة أخرى تكشف عنها عملية توضيح المفاهيم بالمعنى الذي نبغيه، وهي ما نسميه "الحراك المفهومي"، ومؤداه أن بعض المفاهيم تتبادل المراكز فيما بينها بحيث يصبح المفهوم الفرعي مفهوماً أصلياً يحتل مركز الاهتمام، ويحدث ذلك بقصد في أحيان كثيرة، ويكون نتيجة للظروف الاجتماعية والاقتصادية غير المناسبة التي تمر بها الحضارة في حالة ضعفها. مثال ذلك أن هناك تدرجاً في دوائر الانتماء؛ فالدائرة الأولى تبدأ بالفرد نفسه، ثم تتسع الدائرة الثانية لتشمل العائلة، ثم الثالثة لتشمل الوطن، ثم الرابعة لتشمل الأمة حيث العقيدة هي الرابط الأساسي بغض النظر عن الوطن واللغة، ثم الخامسة لتشمل الإنسانية جمعاء

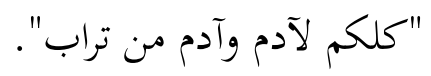

ولكن الذي حدث للأمة بعد أن أخذت تنقل عن الغرب نقلاً لا تقيده الضوابط الشرعية، هو أن مفاهيمها تبادلت المراكز فيما بينها، فبعد أن كان مفهوم "العقيدة" هو المفهوم الأصلي والجذر في شجرة المفاهيم -إذا خينا مفهوم الإنسانية جانباً إذ لا خلاف فيه- أصبح أحد فروع الشجرة وصار ينظر إليه لا على أنه الأصل أو الجذر، بل أصبح الفرد هو المحور وكل ما عداه لا قيمة له، وكل ما نعاني منه الآن هو طراز غريب من النزعة الفردية نشأ نتيجة تبني فلسفات مثل الوجودية الملحدة عند سارتر وغيره من الوجوديين الذين ترجمت معظم أعمالهم إلى العربية دون نقد أو تمحيص، فهذه الفلسفة ترفع الفرد إلى أعلى سلى سريل عليين بحيث تضعه مكان الله! ولو وقف الأمر مع هذه الفردية عند الإعلاء من قيمة الإنسان الفرد لهان الأمر، ولكنه بتاوز ذلك إلى الحد الذي أصبح معه الإنسان هو المشرع للخير والشر والحق والباطل. وانظر معي إلى ما يشرعه الإنسان لنفسه في ظل الحضارة الغربية المعاصرة، تجد أنه يشرع قوانين للواط وقوانين للسحاق! ولم تخل المجتمعات المسلمة من شرذمة تقوم بين ظهرانيها لتدعو إلى ما ينافي العقل والشرع معا، كما أها لم تخل من كتابات تدعو إلى تأسيس الأخلاق على العقل وليس على الدين وذلك باسم العلمانية. وتأتي عملية توضيح المفاهيم لتبين لنا الوظيفة التي يقوم بها المفهوم وموقعه من النسق المعريف الذي ينتمي إليه، كما أها تكشف عن هذا الانحراف الذي يصيب المفاهيم. 


\section{تحليل بنية المفاهيم}

تتألف بنية أي مفهوم من مجموعة من العناصر المكونة له، وهذه العناصر لا تأتي بدرجة واحدة من حيث البناء والأهمة، بل هناك عناصر أساسية وأخرى مكملة لما وقد تشتق منها أحياناً؛ والعناصر الأساسية تتمتع بأسبقية منطقية في بنية المفهوم، إذ أها لا تشتق من غيرها وإنما يمكن لغيرها أن يشتق منها، وتشبه هذه العناصر الأساسية من هذه الزاوية المصادرات أو البديهيات في الأنساق الرياضية والمنطقية، وهي تتمتع بدرجة أكبر من التجريد إذا ما قورنت بغيرها من عناصر المفهوم.

ويككن أن نلقي على هذه الفكرة أضواء شارحة إذا استعنا بفهم ديكارت عن المادة؛ ينظر ديكارت

إلى الامتداد على أنه الصفة الأساسية للمادة، ويقول في كتابه مبادئ الفلسفة:

"ولكن مع أن كل صفة تكفي لتعريفنا بالجوهر إلا أن في كل جوهر صفة تقوّمِ طبيعته وماهيته وتعتمد عليها جميع الصفات الأخرى؛ وأعني بذلك ن الامتداد في الطول والعرض والعمق هو المقوم لطبيعة الجوهر الجسماني... لأن كل ما يستطاع نسبته إلى الجسم يفترض وجود الامتداد من قبل، ولا يعدو أن يكون اعتماداً على ما هو ممتد.... وعلى ذلك فنحن مثلاً لا نستطيع أن نتصور شكلاً ما لم يكن في شيء متد، ولا حركة إلى في فضاء هو متمد.... ولكننا بالعكس نستطيع أن نتصور الامتداد دون شكل أو دون حركة". 1 وواضح من هذا أن صفة "الامتداد" تشكل "العنصر الأساس" في بنية مفهوم المادة، وتجيء الصفات الأخرى مثل الثقل والصلابة والحركة والشكل لتكون عناصر أخرى لاحقة منطقياً لعنصر الامتداد، أي أن هذه العناصر الأخرى تلزم منطقياً عن عنصر الامتداد وليس العكس. وبعبارة أخرى فإن كون الجسم ذا حركة أو شكل يرجع بالضرورة إلى كونه جسماً متداً، أما كونه متداً فلا يفترض وجود أية صفة أخرى في المادة تسبقه منطقياً.

وفضلاً عن التوضيح السابق لفكرة العناصر الأساسية والعناصر الإضافية في بنية المفاهيم، يمكن الإفادة في توضيحها أيضاً من فكرة تصنيف أنواع المعنى في علم الدلالة؛ إذ ميز علماء الدلالة بين عدة أنواع يأتي في مقدمتها المعنى الأساس والمعنى الإضافي. فالمعنى الأساس أو المركزي هو الذي يمثل العامل الرئيس في رينيه ديكارت: مبادئ الفلسفة، ترجمه وقدم له وعلق عليه د. عثمان أمين (القاهرة: مكتبة النهضة المصرية، 1960)، ص149. 
الاتصال اللغوي، والمعبِّر الحقيقي عن أه وظائف اللغة، وهي التواصل ونقل الأفكار. ولكي يتم التواصل بين شخصين بلغة معينة لا بد من أن يشتركا في المعنى الأساس. أما المعنى الإضافي أو الثانوي فهو المعنى الذي تملكه الكلمة زيادة على معناها الأساس، وربما يتغير من عصر إلى آخر تبعاً لتغير المناخ الثقافي الذي تحيا فيه

لغة معينة.

وتبعاً لذلك إذا شئنا فهماً أفضل لبنية أي مفهوم، فيجب أن نحل هذه البنية ونحدد عناصرها

الأساسية وعناصرها الفرعية. ولكي نوضح مدى أهمية هذه العملية التحليلية في الإدراك الدقيق والصحيح للمفاهيم واجتناب اللبس وتفادي الخلاف، يمكن أن نتأمل قليلاً مفهوم "العقل". إذا طرحنا هذا المفهوم للمناقشة طرحاً أولياً دون تحليل لبنيته، فسرعان ما يظهر النزاع بين من يؤيد وجود العقل ومن ينكر وجوده، ولكن إذا حللنا بنية هذا المفهوم وأوضحنا أنه ينقسم على وجه التقريب إلى ثلاث عائلات من المفاهيم هي: المفاهيم المعرفية مثل العلم والفهم والتفكر والإدراك، ومفاهيم الإرادة مثل العزم والاختيار والقصد؛ ومفاهيم الإحساس مثل الغضب والخوف، وللذة والألم؛ أقول: إذا حللنا بنية مفهوم العقل على هذا النحو فإن الحوار الذي يدور حوله سوف تتغير طبيعته وطريته والنتائج التي يمكن أن ينتهي إليها.

ولقد أدرك الفلاسفة المسلمون أن هناك علاقة بين بنية اللغة وبنية العقل وبنية الواقع، يقول أبو حامد الغزالي: "إن للأشياء وجوداً في الأعيان فهو الوجود الأصلي الحقيقي، والوجود في الأذهان هو الوجود العلمي الصوري، والوجود في اللسان هو الوجود اللفظي الدليلي. فإن السماء مثلاً لها وجود في عينها ونفسها، ثم لها وجود في أذهاننا ونفوسنا لأن صورة السماء حاضرة في أبصارنا ثم في خيالنا... أما الوجود في اللسان فهو اللفظ المركب من أصوات... فالقول دليل على ما في الذهن، وما في الذهن صورة لما في الوجود مطابقة له. ولو لم يكن وجود في الأعيان لم ينطبع صورة في الأذهان، ولو لم ينطبع صورة في الأذهان لم يشعر بها إنسان، ولو لم يشعر الإنسان لم يعبر عنها اللسان. وإذن فاللفظ والعلم والمعلوم ثلاثة أمور متباينة لكنها متابقةمتوازية". 2

$$
2 \text { 2 } 2
$$


وإذا كان تحليل بنية المفهوم قد كشف عن وجود عناصر أساسية وأخرى إضافية في المفاهيم، وكشف أيضاً عن وجود علاقة بين بنية المفهوم في الذهن وبنية المفهوم في اللغة أو اللسان، فإن هذا التحليل يكشف وسف لنا كذلك عن وجود بجموعة من المفاهيم تكتسب مع الأيام بعض العناصر الإضافية التي تزيد من مضموها ومن مساحة تطبيقها بحيث تبدو في ناية الأمر كأفا شيء مختلف عما كانت عليه أول الأمر. ومن أمثلة هذه المفاهيم الديمقراطية والحرية. فالديمقراطية، مثلاً، لا تفهم فهماً جيداً إلا إذا كان معناها مقروناً بزمن استعماها، فنقول: إن الديمقراطية عند اليونان تعني كذا وكذا، وفي عصرنا تعني كذا وكذا.

أم عن مفهوم الحرية فحدث ولا حرج، فها هو ذا واحد من أبرز الفلاسفة المعاصرين الذين اهتموا بمفهوم الحرية وهو الفيلسوف الإنجليزي "إزايا برلين " Sir Isaiah Berlin يقول في كتابه أربع مقالات في الحرية: إنه "لن يناقش أكثر من مئتي تعريف للحرية". 3ؤبسط حريات الإنسان أن يكون حراً في جسده يتصرف فيه كيف يشاء، ثم يترتب على هذه الحرية الجسلدية حرية أخرى هي حرية الإرادة، فيختار من بين بدائل كثيرة ما يختاره، وعلى أساس هذه الحرية تقع عليه تبعة الاختيار . وفضلاً عن هذين الجانبين من الحرية، هناك جوانب أخرى لا حصر لها، فهناك حرية العقل، وحرية التعبير، وحرية الفكر، وحرية الصحافة، وحرية الأديب، وحرية العالم في وضع الفروض التي يبدأ منها عملية تفكيره وهلم جرا.

وهذا الجانب الأخير من الحرية لم يكن معروفاً عند أسلافنا من بني البشر، فازداد به مفهوم الحرية خصوبة في المضمون وثراءً في المعنى، وهو الجانب الذي ظهر في أوساط القرن الماضي على أيدي بعض علماء الرياضة وترتب عليه إنشاء هندسات لا إقليدية.4

يتضح مما أسلفناه أن تحليل بنية المفهوم يكشف عن أن بعض المفاهيم تتألف من عناصر محورية أساسية وعناصر أخرى تطرأ على المفهوم خلال سيرورته الفكرية التاريخية، الأمر الذي يفرض على القائم بعملية تحليل المفاهيم أن يضع نصب عينيه دائماً بعض الدلالات التي تكتسبها المفاهيم في مراحل تاريخية معينة، مما قد يحرك الدلالة الأساسية إلى الهامش ويدفع بالدلالة الإضافية إلى المركز.

Berlin, Isaiah: Four Essays on Liberty, (Oxford University Press, 1975), p121. 3 4

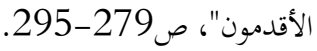




\section{المفاهيم ومشكلة المعنى}

لقد انتهى بنا البحث في بنية المفاهيم ومحاولة توضيحها إلى البحث في دلالة المفاهيم، ذلك أن المفهوم الواضح -كما أشرنا- هو المفهوم الذي ينطوي على معان واضحة ومحددة، والمفهوم الغامض هو الذي انبهمت معانيه بجيث يتعذر علينا إدراكها أو التمبيز بينها في حالة تنوعها، وهنا ينشأ السؤال الذي يربط المفاهيم بمشكلة المعنى: كيف نحكم على المفاهيم بأها واضحة أو غامضة أو خالية من المعنى؟ إنه مفهوم "المعنى" في حد ذاته استوقف أنظار المفكرين متسائلين: ما الذي نريده على وجه الدقة عندما نقول عن جملة: إها ذا ت معنى، وعن جملة أخرى إها خالية من المعنى؟ عندما نمعن النظر في هذا السؤال نجد أنه ليس يسيراً، ذلك لأن بجالات الكلام متعددة، فهناك مجالي الأدب والفن، وبجال العقائد والقيم، وبجال العلوم الطبيعية، وبحال العلوم الرياضية والمنطقية. ولعل العجز عن إدراك نوع المعنى في كل مجال من هذه المجالات هو الذي أفضى إلى نوع من "القلق الدلالي" الذي يتجلى عند بعض المدارس الفكرية وبخاصة التيارات المادية التي تقصر المعنى على بجال واحد فحسب وتصف غيره بالهراء. وسنشير فيما يلي إلى بعض الآراء في مشكلة المعنى في التراث الإسلامي وفي علم اللغة ويف فلسفة اللغة، ونوضح إلى أي حد تؤثر تلك الآراء في التعامل مع المفاهيم، ثم نحاول الوقوف على سبب ما يبهوز أن نسميه "بالأمراض الدلالية" التي تصيب المفاهيم، وكيف يمكن معالجتها.

لقد ظهر الاهتمام بقضية المعنى في التراث العربي الإسلامي في حقول معرفية متنوعة، حيث نجده بارزاً في البلاغة والفلسفة وعلم اللغة وعلم أصول الفقه. وليس في وسعنا أن نفصل القول في هذه المجلات، وحسبنا أن نشير إشارة موجزة إلى عناية الفكر الإسلامي بمشكلة المعنى التي تعد إحدى الركائز المهمة في دراسة المفاهيم.

خصص ابن جني في كتابه الخصائص باباً أسماه "في الرد على من ادعى على العرب عنايتها بالألفاظ وإغفاها المعاني"، قال فيه: "وذلك أنَّ العرب كما تعني بألفاظها فتصلحها وتمذها وتراعيها، وتلاحظ أحكامها بالشعر تارة، وبالخطب أخرى، وبالأسجاع التي تلتزها وتتكلف استمرارها، فإن المعاني أقوى عندها، وأكرم عليها، وأفخم قدراً في نفوسها؛ فأول ذلك عنايتها بألفاظها، فإنها لما كانت عنوان معانيها، 
وطريقاً إلى إظهار أغراضها، ومراميها، أصلحوها ورتبوها، وبالغوا في تحبيرها وتحسينها، ليكون ذلك أوقع لها في السمع، وأذهب بها في الدلالة على القصد؛ ألا ترى أن المثَّلَ إذا كان مسجوعاً لذّ لسامعه فحفظه، فإذا هو حفظه كان جديراً باستعماله، ولو لم يكن مسجوعاً لم تأنس النفس به... وإذا كان كذلك لم تحفظه، وإذا لم تحفظه لم تطالب أنفسها باستعمال ما وضع له... فإذا رأيت العرب قد أصلحوا ألفاظها وحسنوها.... فلا تَرَيَنَّ أن العناية إذا ذاك إنما هي بالألفاظ، بل هي عندنا خدمة منهم للمعاني، وتنويه بها...، ونظير ذلك إصلاح الوعاء وتحصينه، وتزكيته وتقديسه، وإنما المُنْيُّ بذلك منه الاحتياط للموعى عليه، وجواره بما يعطر

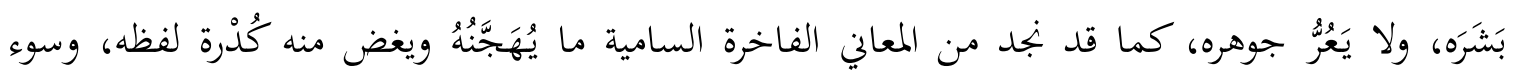

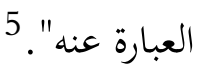

وبناء على ذلك اهتم اللغويون العرب بدلالة الألفاظ، ويتجلى هذا في تسجيل معاني الغريب في القرآن الكريع، ودراسة المجاز فيه. وجاءت عملية ضبط المصحف لتمثل في ذاتما عملاً دلالياً عظيماً، إذا إن تغيير ضبط الكلمة يفضي إلى تغيير وظيفتها، وبالتالي تغيير معناها. وأبسط مثال نسوقه هنا هو السبب

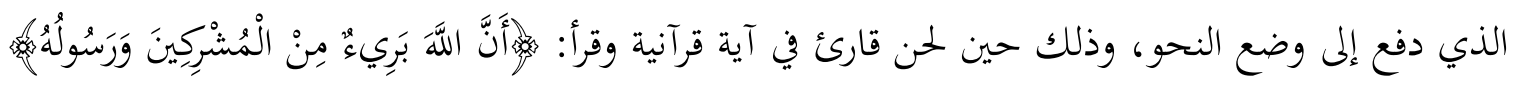
(التوبة: 3) بجر كلمة "رسول" بدلاً من ضمها، ويترتب على هذه القراءة أن يبرأ الله من رسوله بدلاً من أن يكون الرسول هو البريء من المشركين.

ولننظر أولاً في ججال البلاغة: اهتم البلاغيون بدراسة كثير من الجوانب الدلالية مثل الحقيقة والمجاز، ودراسة الأساليب كالأمر والنهي والاستفهام والتعجب وغيرها. وسنكتفي بفكرة واحدة هي فكرة "النظم" عند عبد القاهر الجرجاني (ت: 471هـ/1079م).

طرح برتراند رسل في كتابه بحث في المعنى والصدق سؤالاً مؤداه: ما الذي يضفي الوحدة على الجملة المفيدة؟ ليس من شك في أن هناك رابطاً منطقياً يربطها، وهذا الرابط المنطقي يتمثل في طريقة "تتيب" المفردات داخل الجملة. والمعنى عند رسل إذن يكمن في طريقة الترتيب التي تنظم هها المفردات، لا في

ابن جنيّ، أبو الفتح الموصلي (ت392هـ/1002م): الخصائص: تعقيق محمد علي النجار (القاهرة: الميئة المصرية العامة للكتاب،

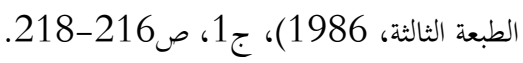


المفردات من حيث هي كذلك. هذا ما قاله رسل في القرن العشرين، لكن انظر إلى ما سبق أن قاله الجرجالي في كتابيه أسرار البلاغة ودلائل الإعجاز بتحد الفكرة نفسها، بل إها عنده أكثر وضوحأ.

الحق أن فكرة النظم ظهرت عند السابقين على الجرجاني، ولكنها ارتقت عل يديه حتى صارت نظرية تميز بها. والمتأمل في كتاب دلائل الإعجاز، مثلاً يجد أنه لا يفرق بين معاني النحو والنظم، بل يؤكد أن النظم في جوهره هو النحو في أحكامه، ليس من حيث الصحة والفساد فقط، بل من حيث المزية والفضل، يقول: " واعلم أن ليس النظم إلا أن تضع كلامك الوضع الذي يقتضيه علم النحو وتعمل على قوانينه وأصوله، وتعرف مناهجه التي فجت فلا تزيغ عنها... فلست بواجد شيئاً يرجع صوابه إن كان صواباً وخطؤه إن كان خطأ إلى النظم، ويدخل تحت هذا الاسم، إلا وهو معنى من معاني النحو قد أصيب به موضعه ووضع في حقه، أو عومل بخلاف هذه المعاملة فأزيل عن موضعه، واستعمل في غير ما ينبغي له، فلا ترى كلاماً قد وصف بصحة نظم أو فساده أو وصف بمزية وفضل فيه إلا وأنت بحد مرجع تلك الصحة وذلك الفساد وتلك المزية وذلك الفضل إلى معاني النحو وأحكامه، ووجدته يدخل في أصل من أصوله، ويتصل بباب من أبوابه".6 ويؤكد الجرجاني الفكرة ذاتما في كتابه أسرار البلاغة إذ يقول: "الألفاظ لا تفيد حتى تؤلف ضرباً خاصاً من التأليف، يعمد بها إلى وجه دون وجه من التركيب والترتيب"، 7 ويوضح ذلك فيقول: إنك لو أخذت بيتاً من الشعر أو فصلاً من النثر وعددت كلماته عداً مبطلاً نظام تلك الكلمات الذي بنيت عليه العبارة من كمال البيان إلى مجال المذيان، نحو أن تقول في: "قفا نبك من ذكرى حبيب ومنزل" منزل قفا ذكرى من نبك حبيب". والسؤال الذي ينشأ هنا هو: لماذا كان ترتيب اللفظ على نهو معين قدر على البيان؟ والجواب عند الجرجاني: هو أن ترتيب اللفظ على هذا النحو المعين إنما يساير الترتيب نفسه الذي انتظمت به المعاني في ذهن المتكلم، ولقد انتظمت المعاني وفق ما يقتضيه العقل، فلمنطق العقلي

عبد القاهر الجرجاني (ت: 471هـ/1079م): دلائل الإعجاز في علم المعاني، صححه وعلق عليه محمد رشيد رضا (القاهرة: مكتبة

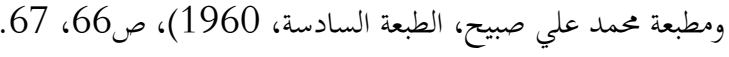
عبد القاهر الجرجاني: أسرار البلاغة في علم البيان، صححه وعلق عليه محمد النجار (القاهرة: مكتبة ومطبعة محمد علي صبيح، 
نفسه يدلك على أن المعاني يجب أن تسبق،وأيها يجب أن تأتي لاحقة، بحكم طبائعها بالنسبة للموقف الذي نقفه من عالم الأشياء، فالمبتدأ يجب أن يسبق ليلحق به الخبر، والفاعل يجب أن يسبق ليلحق به مفعوله. 8 وفي مجال الفلسفة نجد عناية فلاسفة الإسلام بقضية اللفظ والمعنى واضحة في كتابات الكندي والفارابي وابن سينا وابن رشد وابن حزم والغزالي؛ فكثيراً ما تشتمل أبحاثهم المنطقية واللغوية على باب مؤداه "دلالة الألفاظ ونسبتها إلى المعاني"، وغالباً ما يقررون أن الألفاظ تدل على المعاني من ثلاثة أوجه متباينة، يقول ابن سينا في الإشارات والتنبيهات: إن اللفظ يدل على المعنى:

إما على سبيل المطابقة، بأن يكون ذلك اللفظ موضوعاً لذل المعنى وبإزائه، مثل

$$
\text { دلالة "المثلث" على الشكل المخيط به ثلاثة أضلع. }
$$

2) وإما عل سبيل التضمن بأن يكون المعنى جزءاً من المعنى الذي يطابقه اللفظ مثل

$$
\text { أنه اسم لمعنى جزؤه الشكل. }
$$

3) وإما على سبيل الاستتباع والالتزام، بأن يكون اللفظ دالاً بالمطابقة على معنى، ويكون ذلك المعنى يلزمه معنى غيره كالرفيق الخارجي، لا كالجزء منه، بل هو مصاحب ملازم له.

$$
\text { مثل دلالة لفظ "السقف" على "الحائط". و "الإنسان" على قابل صنعة الكتابة. } 9
$$

أما عن نسبة الألفاظ إلى المعاني فيقول الإمام أبو حامد الفزالي: "اعلم أن الألفاظ من المعاني على أربعة منازل: المشتركة، والمتواطئة، والمترادفة، والمتزايدة. أم المشتركة فهي اللفظ الواحد الذي يطلق على موجودات مختلفة بالحد والحقيقة إطلاقاً متساوياً كالعين تطلق على العين الباصرة، وينبوع الماء وقرص الشمس، وهذه مختلفة الحدود والحقائق. وأما المتواطئة فهي التي تدل على أعيان متعددة بمعنى واحد مشترك بينها، كدلالة اسم الإنسان على زيد وعمرو، ودلالة اسم الحيوان على الإنسان والفرس والطير لأهفا متشاركة في معنى الحيوانية والاسم بإزاء ذلك المعنى المشترك المتواطئ، بخلاف العين الباصرة وينبوع الماء. وأما المترادفة فيه الأسماء المختلفة الدالة على معنى يندرج تحت حد واحد كالخمر والراح والعقار، فإن المسمى بهذه يجمعه

$$
\begin{aligned}
& 8 \\
& \text { أبن سينا (ت: 428هـ/137م): الإشارات والتنبيهات، مع شرح نصير الدين الطوسي، القسم الأول، تحقيق د. سليمان دنيا } \\
& \text { (القاهرة: دار المعارف، الطبعة الثالثة، 1983)، ص137م) الإنات }
\end{aligned}
$$


حد واحد وهو المائع المسكر المعتصر من العنب والأساس مترادفة عليه. وأما المتزايلة فهي الأسماء المتباينة التي ليس بينها شيء من هذه النسب كالفرس والذهب والثياب، فإنها ألفاظ مختلفة تدل على معان مختلفة بالحد والحقيقة. 10

وأما الأصوليون فقد اهتموا بدراسة اللغة بصفة عامة والمعنى على وجه الخصوص، ويرجع ذلك إلى وجود صلة وثيقة بين فهم اللغة والمعنى وفهم الشرع المستمد من القرآن الكريع والسنة المطهرة. ويعرف علم الأصول بأنه علم استنباط الأحكام الشرعية من أدلتها التفصيلية. وبالتالي يرتكز موضوعه على محورين هما الأدلة والأحكام. وتقتضي عملية استنباط الأحكام الشرعية من الأدلة معرفة معاني الألفاظ بغية معرفة المقصود من نصوص القرآن الكريم والسنة المطهرة.

وإذا كان اللغويون قد وضعوا المعنى في منزلة أعلى من اللفظ كما اتضح من نص ابن جني الذي اقتبسناه آنفاً، فإن الأصوليين يسيرون في هذا الاتحاه أيضاً، وها هو ذا الثاطبي (790هـ/1388م) يقول في الموافقات في أصول الأحكام: "واللفظ إنما هو وسيلة إلى تحصيل المعنى المراد، والمعنى هو المقصود". 11 وهناك اتفاق بين الأصوليين والفلاسفة على كيفية دلالة الألفاظ على المعاني، فكما حدد ابن سينا هذه الدلالة في ثلاثة أوجه هي المطابقة والتضمن والاستباع والالتزام، كذلك حددها الغزالي في المستصفى بالأوجه نفسها السابقة. 12 وقسم الأصوليون الألفاظ المفردة فحسب، بل تناولوا دراسة الصيغ أو العبارات، واهتموا اهتماماً بالغاً بصيغتي الأمر والنهي في القرآن الكريم لكوغما محور التكليف. وهنا نجد أن الأصوليين يأخذون بنظرية الاستعمال أو السياق، على أساس أن الاستعمال أو السياق هو الذي يحدد دلالات هاتين الصيغتين. ونورد فيما يلي بعض المعاني الواضحة لصيغة الأمر التي وصلت إلى عشرين معنى أو يزيد:13

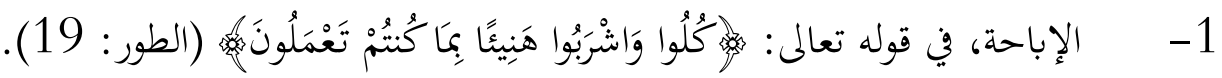

$$
\begin{aligned}
& 10
\end{aligned}
$$

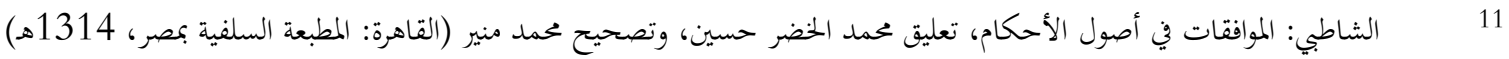

$$
\begin{aligned}
& \text { ج2، ص57. }
\end{aligned}
$$

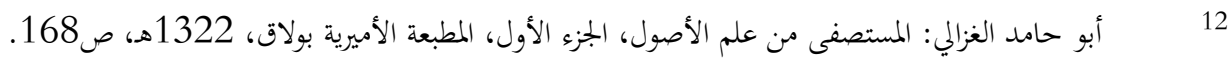

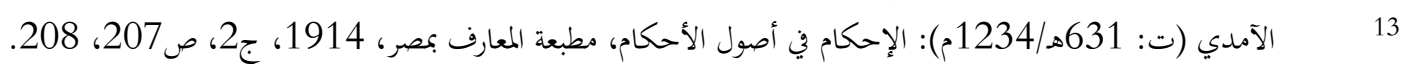




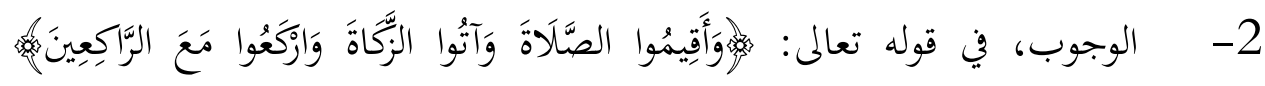

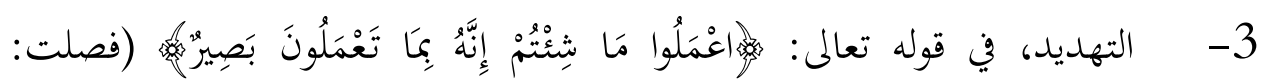

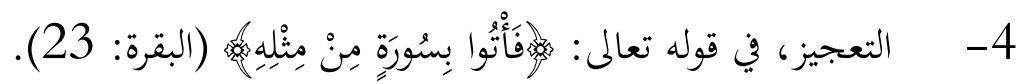

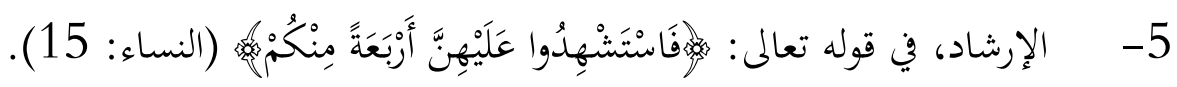

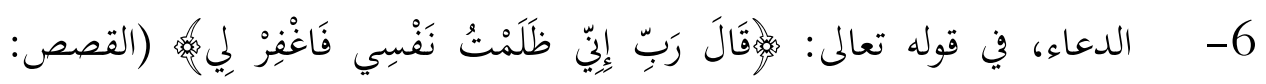

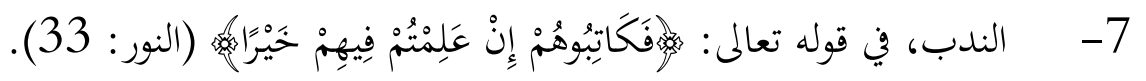

$$
\text { وهناك وجوه كثيرة تفيدها صيغة النهي نذكر منها:14 }
$$

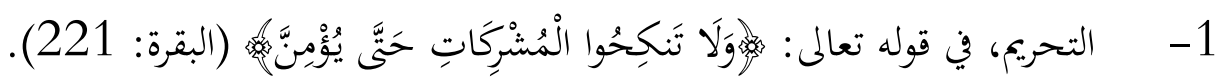

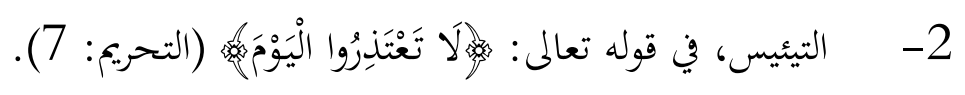

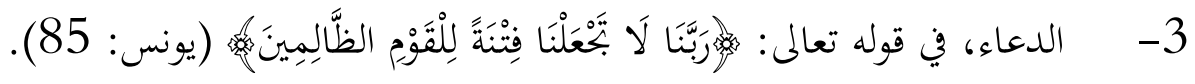

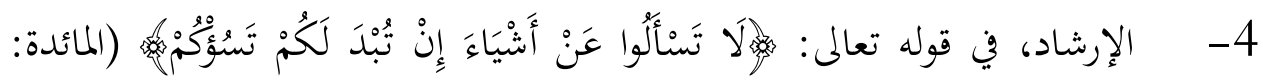

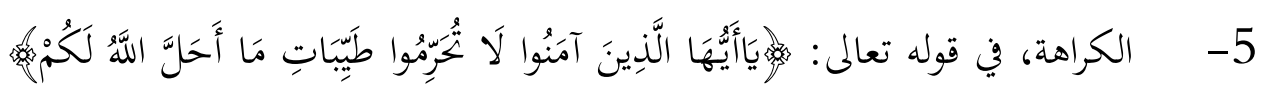

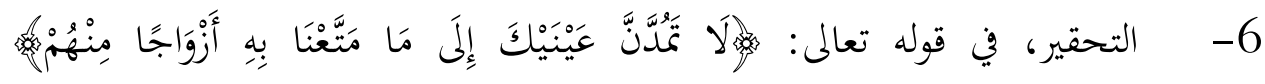
(الحجر: (88)

وإذا نظرنا إلى الفكر الغربي المعاصر، وجدنا أن مشكلة المعنى قد حظيت باهتمام كبير في كل من علم

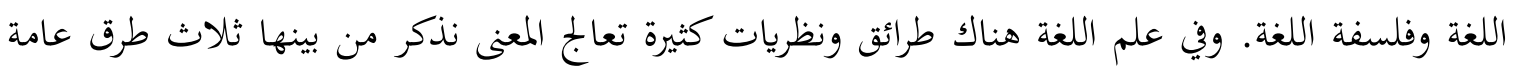

$$
14
$$


هي: التحليل القائم على المصاحبة اللفظية (collocational analysis) وطريقة المجال الدلالي (semantic field)، وطريقة التحليل العنصري (أي إلى عناصر (collocational analysis). يتضمن التحليل القائم على المصاحبة اللفظية دراسة الظهور المشترك لمفردات معجمية منفصلة مع مفردات معجمية أخرى منفصلة. فعلى سبيل المثال، عندما يختبر المرء مجموعة كبيرة -ولنقل مئة كتاب- في موضوعات متنوعة، فسوف يكتشف أن كلمة "ليل" تتصاحب لفظياً، أي تظهر في نفس العبارة، مع "مظلم" و "أسود" و"وقت" و "منتصف" و"يهبط"، وبعض هذه الكلمات تتصاحب بدورها مع "هار" و "صباح" وهلم جرا. وبهذه الطريقة يستطيع المرء بناء فئات تقوم على المصاحبة اللفظية، فالكلمات "مظلم"" و "أسود" و "وقت" و "منتصف" تشكل فئة تقوم على المصاحبة اللفظية لأهما تتصاحب جميعاً مع كلمة "ليل"، وتشكل الكلمات "هار، ليل، صباح" وهلم جرا، فئة تقوم على المصاحبة اللفظية لأها تظهر مع "منتصف". ويختلف التحليل القائم على المصاحبة اللفظية عن النحو، فالنحو يعالج فئات من المفردات ولا يعالج الكلمات المنفصلة؛ فالفئات النحوية: اسم وفعل وحرف وهلم جرا، تتضمن آلاف الكلمات التي ليس لها علاقات متبادلة ذات أهمية دلالية. وقد زعم فيرث، على سبيل المثال، أن قائمة المصاحبات اللفظية بالنسبة لكل كلمة هي جزء من معناها. 15 وواضح أن هذه الطريقة تعوّل إلى حد ما على فكرة السياق اللغوي.

وتوضح نظرية المجال الدلالي وجهة النظر القائلة بأنه لكي نفهم معنى كلمة معينة، فلا بد من أن نفهم أيضاً بجموعة الكلمات المرتبطة بها دلالياً، وهذه المجموعة من الكلمات تكوّن مجالاً معجمياً أو دلالياً، وأمثلة البجالات الدلالية هي القرابة والألوان والنباتات والأمراض. ويف هذا الإطار قدم جون ليونز في كتابيه علم الدلالة البنيوي ومقدمة لعلم اللغة النظري تقريراً حديثاً وشاملاً عن فكرة المجال الدلالي. يعرف ليونز معنى

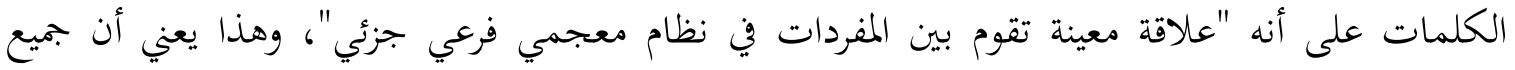
الكلمات في مجال معجمي معين تكون مرتبطة، ولا يأتي ارتباطها بالضرورة بطريقة واحدة. ويرى ليونز أن المجال الدلالي لا بد من أن يتضمن تخصيصاً لعلاقات معينة، ومن بين هذه العلاقات الترادف

Lehrer, A.: "Meaning in Linguistics", In theory of Meaning, edited by Adrienne and Keith Lehrer, (Englewood Cliffs, New Jersey: Prentice - Hall, 1970), p13. 
(antonymy) والتضمين (inclusion). والتضاد (synomymy) السيف والمهند، والتضاد مثل الحب والكراهية، والتضمين الذي هو علاقة لزوم أحادية الطرف مثل قولنا: إن "تفاحة" تستلزم "فاكهة"، وليس العكس؛ ويمكن أن نضيف إلى هذه العلاقات علاقة التضايف (correlation) ) وهي خاصية لحدين أو كلمتين تجمعهما صلة متبادلة بحيث لا نتصور أحدهما دون تصور الآخر مثل الأبوة والبنوة، والأعلى والأسفل، والأستاذ والتلميذ.

على أن فكرة المجال الدلالي ليست وليدة علم اللغة الحديث، وإنما هي فكرة قديمة عرفها اللغويون المسلمون وفطنوا إليها وسبقوا بها الأوربيين بعدة قرون وإن لم يعطها أحد منهم هذا الاسم. فقد قام اللغويون المسلمون بوضع رسائل اقتصر بعضها على بجال دلالي واحد كخلق الإنسان، أو الإبل، والخيل، والوحوش، والحشرات، والنبات، الشجر، والمطر، والأزمنة. وكانت هذه الرسائل النواة الأولى لمعاجم المعاني المرتبة على حسب الموضوعات، تلك التي سبق بها المعجميون المسلمون غيرهم من الأوربيين بمئات السنين، وبعض هذه المعاجم ميمل فكرة المجال الدلالي مثل الغريب المصنَّف لأبي عبيد القاسم بن سلام (توفي: 224هـ/839م)، ومبادئ اللغة للإسكافي (توفي: 421هـ/1030م،) وفقه اللغة للنعابي (توفي: 430هـ/1039م)، والمخصص لابن سيده (توفي: 458هـ/1066م).

أما الطريقة الثالثة من الطرق العامة التي يعالج بها علم اللغة مشكلة المعنى فهي التحليل على أساس العناصر، ومؤدى هذه الطريقة أن المعنى الكلي للكلمة يمكن إدراكه في حدود بجموعة من العناصر المتميزة أو مكونات المعنى. إن علماء اللغة والأنثروبولوجيا الذين استعملوا هذا المنهج قد قبلوا بصورة ضمنية نظرية المجال وذلك بأن استهلوا تحليلهم بمجموعة من المفردات المعجمية المترابطة، ومع ذلك فإفهم قاموا بعزل "عناصر" معينة متكررة عادة بدلاً من أن يعينوا العلاقة المتبادلة بين المفردات. 18

Ibid, p.14. 16

17 18 Lehrer, A. op. cit. and see also J. Lyons: Semantics (London/ New York: 
ويمكن أن ندرك العناصر بسهولة حين يمكن عرض الكلمات في صورة تخطيطية لتمثل نوعاً من العلاقة

التناسبية، وهناك تقسيم ثلاثي تشترك فيه كثير من اللغات فيما يتعلق بكثير من الكلمات التي تشير إلى

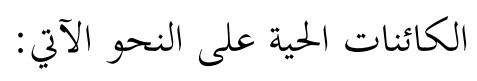

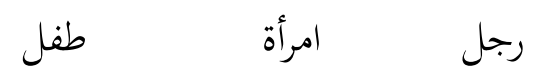

ثور

كبش

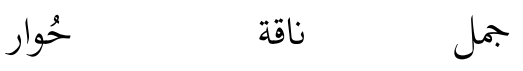

وهكذا يكون الثور بالنسبة للبقرة كما يكون الكبش بالنسبة للنعجة. وفي ضوء مثل هذه العلاقات نستطيع أن نفصل عناصر مثل "ذكري" و "أنثوي"، و "بالغ" و"دون البلوغ"، و "إنساني" و "بقري" و "غنمي" و "جملي". وهذا النوع من "التحليل على أساس العناصر" يجيز لنا أن نقدم تعريفات لجميع هذه الكلمات في حدود قلة من العناصر، وبالتالي فإن تعريف كلمة"رجل" هو "إنساني" و "ذكري" و "بالغ" وهلم جرا. 19 وهناك محاولات قام بها كاتز وفودر لتحليل عناصر المعاني لبعض الكلمات في اللغة الإنجليزية وذلك من خلال النظر في بنية المعجم، إذ يسند المعجم معنى أولياً إلى المفردات اللغوية ويخصها بسمات صوتية وتركيبية ودلالية، ويتحدد معنى المفردات عن طريق المدخل المعجمي. ويوصف المدخل المعجمي بأنه مركب من المؤشرات النحوية (grammatical markers) مثل اسم، وفعل، وصفة، والمؤشرات الدلالية (demmantic markers)

Palmer, F. R.: Semantics, (Cambridge: Cambridge Unveristy Press, 1981), pp 109- 
المحدة مثل "لم يتزوج أبداً". وقد قدم كاتز وفودر تحليلاً لكلمة "أعزب" (bachelor) في اللغة الإنجليزية على النحو الآتي:20

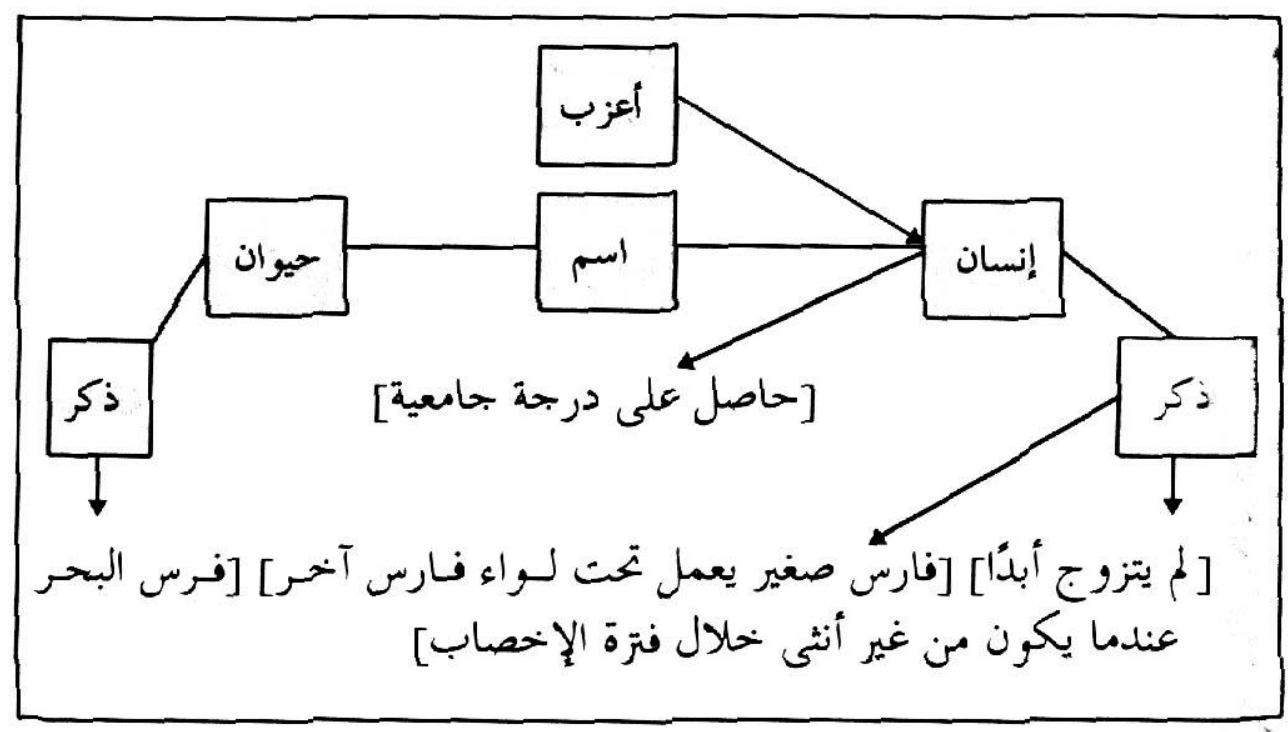

وعلى هذا النحو يستطيع عالم اللغة أن يهدد معنى كل كلمة عن طريق تقديم المدخل المعجمي الخاص

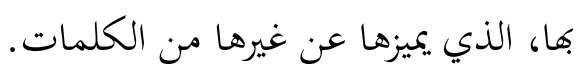

وعندما نتتقل إلى بجال الفلسفة نجد أن فكرة المعنى هي المحور الذي دارت حوله الفلسفة المعاصرة، إذ لم تشغل هذه الفكرة الفلسفة التحليلية فحسب، بل شغلت أيضاً الفلسفات غير التحليلية مثل الفينومينولوجيا والبراجماتية والبنيوية والفلاسفة الأحياء مثل ديفيدسون وسيرل وكاتز ودميت وغيرهم. ولسنا في

Katz, J. J., and J. A. Fodor: The Structure of Language: Readings in the Philosophy of Language, (Englewood Cliffs, N.J.: Prentice-Hall, 1964), p496. 
حاجة إلى الوقوف طويلاً عند التصنيفات التي يقدمها الفلاسفة لنظريات المعنى، 21 وحسبنا أن نشير إلى نظريتين مهمتين هما نظرية التحقق(verification theory)، ونظرية الاستعمال (use theory). أما نظرية التحقق فقد دافعت عنها مدرسة أثارت جدلاً كبيراً في الفكر المعاصر، وهي الوضعية المنطقية التي عرفت بعدة أسماء أخرى مثل "التجريبية العلمية" و"الفلسفة الوضعية الجديدة"، وضمت مجموعة من الفلاسفة مثل شليك وفايزمان وكارناب وفايجل وآير وغيرهم. وجرى الاتفاق بين هؤلاء الفلاسفة على المبدأ القائل بأن معنى الجملة هو منهج التحقق منها. وسمي هذا المبدأ باسم مبدأ التحقق verification) (principal) يقول شليك: "كلما نسأل عن جملة (ماذا تعني؟)، فإننا نتوقع درساً فيما يتعلق بالظروف التي تستعمل الجملة فيها، ونود أن نصف الشروط التي سوف تشكل الجملة بمقتضاها قضية (صادقة) والشروط التي تجعلها (كاذبة)... ومعنى القضية هو منهج تحققها". 22 ويؤكد وايزمان الفكرة نفسها بعبارة أخرى فيقول: "لكي يكصل المرء على فكرة عن معنى القضية، فمن الضروري أن يكون واضحاً بشأن الإجراء الذي يؤدي إلى تحديد صدقها، وإذا لم يعرف المرء هذا الإجراء، فلا يمكن له أن يفهم القضية أيضاً... إن معنى القضية هو منهج تحققها". 23 وقد انصب اهتمام فلاسفة الوضعية المنطقية على تحليل القضية بوصفها أدنى حد يمكن أن ينحل إليه الكلام المعقول، والقضية عندهم هي العبارة التي يجوز وصفها بالصدق أو الكذب، بيد أن الصدق والكذب يختلف معناهما باختلاف نوع العبارة، ولا تخرج العبارات التي يمكن وصفها بالصدق أو بالكذب عن أحد نوعين، فهي إما "تحليلية" وإما "تركيبية". ولا تقول العبارة التحليلية شيئاً جديداً عن الموضوع الذي تتكلم عنه، وكل ما تفعله هو أن تحلل هذا الموضوع إلى عناصره بعضها أو كلها. ومن أمثلة هذا النوع: "الأرملة امرأة مات زوجها"، و"الزاوية القائمة تسعون درجة"، و"الأعزب رجل غير متزوج". أما العبارة التركيبية فهي التي تقول لنا خبراً جديداً عن الواقع يمكن أن نتبت من صدقه أو كذبه بالرجوع إلى هذا الواقع وإجراء

$$
21 \text { 1995)، ص176 مانظر التصنها. }
$$

Schlick, M.: "Meaning and Verification", in A. Lehrer and K. Lehrer (eds.): The

Theory of Meaning (Englewood Cliffs, N. J.: Prentice-Hall, 1970), pp. 100-101. Waismann, F. Verification and Definition (Oxford: Basil Blackwell, 1981), p27. 
مقارنة بينه وبين ما تزعمه العبارة. ومن أمثلة هذا النوع: "الباب مفتوح"، و"الحجرة مضاءة"، و"السماء تمطر".

وتتميز العبارات التحليلية بأها تحصيل حاصل، ويقينية الصدق، ومحك الصدق فيها هو اتساق

موضوعها مع محمولا, أما العبارات التركيبية فهي عبارات تجريبية احتمالية الصدق، ومقياس الصدق فيها هو بحربة الحواس، والعبارات من هذين النوعين هو وحدها العبارات ذوات المعنى عند فلاسفة الوضعية المنطقية.

وإذا نحينا جانباً القضايا التحليلية، تبقى لنا القضايا التركيبة. وطالما أن الشرط الوحيد لقبول القضايا التركيبة هو إمكان وصفها بالصدق أو بالكذب على أساس من خبرة الحواس، فإنه تخرج بذلك من بجال العبارات ذوات المعنى مجموعتان هما:

1 - عبارات الأمر والتعجب والاستفهام والتمني وما جرى بجراها. ومن أخطر النتائج

$$
\text { المترتبة على ذلك استبعاد العبارات الأخلاقية والجمالية. }
$$

2- عبارات الميتافيزيقا التي لا تتحدث عن شيء في الطبيعة بحيث نستطيع أن نطابق

بينها وبين ما تتحدث عنه، وإنما تتحدث بحكم تعريفها عن شيء يجاوز ما هو في الطبيعة.

وهكذا استبعد الوضعيون المنطقيون الميتافيزيقا لا بوصفها عقيمة أو غير علمية كما ذهب إلى ذلك

الفلاسفة السابقون مثل أوجست كونت، وإنما جاء الاستبعاد على أساس أن قضاياها لا تنتمي إلى القضايا التحليلية أو التركيبية. وطالما أننا لا نجد لها من وقائع لعالم ما يجعلها صادقة أو كاذبة، فإنها لذلك عبارات خالية من المعنى. وعلى هذا النحو تحددت مهمة العبارة ذات المعنى -بغض النظر عن قضايا المنطق والرياضيات- في وصف حالة من حالات الواقع، ثم يجيء حكمنا على هذه العبارة بالصدق أو بالكذب بناء على قابليتها للتحقق.

ونظراً لحطورة النتائج التي ترتبت على نظرية التحقق في المعنى، فقد واجهت هذه النظرية اعتراضات قوية انصب بعضها على منطوق مبدأ التحقق ذاته. إذ ذهب بعض النقاد إلى أن عبارة المبدأ ليست علمية يمكن التحقق منها، ومن ثم يمكن رفض المبدأ على أساس أنه خال من المعنى، ولكن أنصار نظرية التحقق 
ردوا على هذه الحجة بما يسمى نظرية الأنماط المنطقية التي مفادها أن العبارات اللغوية ليست من نمط واحد، ولا يكون مقياس الصدق في أحد هذه الأنماط هو المقياس نفسه في النمط الآخر. ويمكن توضيح ذلك بالمثال الآتي: تأمل العبارتين "انكسر الزجاج لأن الرياح عصفت به" و "لكل حادثة سبب"، تجد أننا إذا وصفنا العبارة الأولى بأها عبارة سببية، فلا نستطيع أن نصف الثانية بالطريقة ذاها، لأن مبدأ السبية لا يمكن أن يكون هو نفسه عبارة سبية تتناظر مع العبارات التي تضرب له الأمثلة، وبطريقة مماثلة يجب ألا نتوقع أن يكون مبدأ التحقق بذاته موضوعاً للمعيار الذي يتحكم في رسم العبارات ذوات المعنى.24 وهناك اعتراض آخر ينصب على طبيعة الكائنات التي يطبق عليها المبدأ: هل هي الجمل أم القضايا أم العبارات؟ لو أخذنا الجمل أولا لوجدنا أن هناك صعوبة في النظر إلى الجمل بوصفها صادقة أو كاذبة، ومن ثم كوها قابلة للتحقق أو غير قابلة للتحقق، لأن الجمل تستعمل لقول شيء صادق في مناسبة وكاذب في مناسبة أخرى، مثل الجملة: "إفا تمطر" التي قد تكون صادقة الآن وكاذبة بعد قليل، ومن ثم فإن كلامنا عن منهج التحقق للجمل لا معنى له.

وقد حاول أنصار نظرية التحقق التغلب على هذه الصعوبة فقدموا مصطلحاً آخر هو ذو معنى، لأن أنصار المبدأ يقولون إن القضية التي ليس لها منهج للتحقق ليس لها معنى، وهنا لا يجدي أن نطبق هذا المعيار على القضايا طلما أن القضايا بجكم تعريفها تكون صادقة أو كاذبة. وما يكون صادقاً أو كاذباً لا يكون خالياً من معنى، وبالتالي يجد أنصار مبدأ التحقق أنفسهم أمام معضلة: فإما أن يكون المبدأ حول الجمل، وبالتالي لا يمكن طرح السؤال: "هل هي صادقة؟"، وإما أن يكون حول القضايا وبالتالي لا يمكن طرح السؤال: "هل هي ذوات معنى؟". وخلاصة هذا الاعتراض أن المبدأ إما أنه غير ضروري أو لا سبيل إلى تطبيقه. 25

وفضلاً عن هذه الاعتراضات، هناك اعتراضات على نظرية التحقق في المعنى من زوايا متباينة. فعلى سبيل المثال، نشر كواين Quine في سنة 1951 مقالة بعنوان "عقيدتان للتجريبة"، ذهب فيها إلى أن

Evans, J. L.: “one Meaning and Verification”, Mind, vol. LXII, No. 245, 1953, p3. 24 Hanfling, O.: Logical Positivism (Oxford: Basil Balckwell, 1981), p16. 
العقيدة الأولى هي الاعتقاد بوجود تمييز صارم بين العبارات التحليلية والتركيبية، أما العقيدة الثانية فهي النزعة الردية، أي الاعتقاد بأن كل عبارة ذات معنى تكون مكافئة لبناء منطقي معين يقوم على حدود تشير إلى خبرة مباشرة. ولقد تأسست الوضعية المنطقية على هاتين العقيدتين، وجاء هجوم كواين العنيف عليهما ليضع النهاية لهذه الفلسفة. وناقش كواين في مقالته المشار إليها كل التعريفات المقترحة لمصطلح "تحليلي"، وأثبت أنه دائرية أو أها تعول على مفاهيم أكثر غموضاً من مفهوم التحليلية ذاته، مثل المعنى والترادف. 26 وتبعاً لهذا النقد للتمييز بين التحليلي والتركبي، أخذ كثير من الفلاسفة المعاصرين بالرأي القائل: إن التمييز لا يزيد على أن يكون مسألة درجة.

ومبدأ التحقق هو معيار لتمييز المعرفة العلمية عن اللاعلم أو الميتافيزيقا في رأي أنصار المبدأ، على أساس أن المعرفة العلمية هي المعرفة ذات المعنى، أما اللاعلم فهو اللامعنى. ولكن دعنا ننظر في هذا الأمر م زاوية العلوم التجريبية وفي حدود علم الفيزياء على وجه الخصوص ونتساءل: هل كل جملة لا نستطيع التحقق منه تجرييياً تعد ميتافيزيقية؟ ترتكز الوضعية المنطقية على المنطق الاستقرائي في تحديد معيار التمييز بين الجمل العلمية والميتافيزيقية، وتبدأ من جمل معينة تنظر إليها على أهما أساسُ ومحكُّ لبقية جمل العلم -وهي الجمل الأساسية- ثم تصعد إلى الجمل العامة. وتعد كل عبارة لا تدخل في هذا الإطار عبارة ميتافيزيقية يتعين على

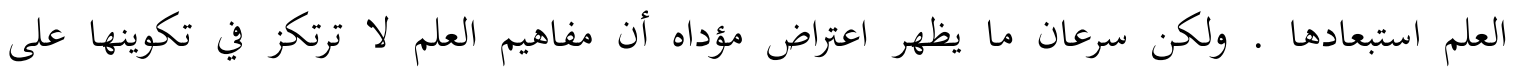
الاستقراء، وإنما هي من إيداع العقل، زد على ذلك أن بناء النظرية العلمية والفيزيائية خاصة يقوم على له الاستدلال أكثر من الاستقراء، وبقدر ما تكون النظرية متسقة تكون قوية ومقبولة.

وفضلاً عن ذلك نجد أن مجموعة كبيرة من المفاهيم والفروض التي لا ترتكز على التحقق التجربي كان لها نصيب كبير في تقدم العلم وتطوره، مما دفع بعض الباحثين إلى بحث الأسس الميتافيزيقية للعلم كما فعل بيرت Burtt في كتابه الأسس الميتافيزيقية لعلم الفيزياء الحديث، إذ تفترض نظريات علمية كثيرة أن الأصل في الكون هو الاتساق والنظام، وأن حركة الموجودات والظواهر فيه تخضع لنظام دقيق، ولعل هذا الانسجام الكامن والظاهر في الكون هو الذي دفع العلماء إلى البحث عن القوانين التي يسير بمقتضاها، كما Quine, W. V.: Form a Logical Point of View (New York: $2^{\text {nd }}$ edition, Harper Torchbooks: The Science Library, 1961), pp. 20-45. 
أن مؤلفات كوبرنيكوس وكبلر ونيوتن تنطوي على فروض ميتافيزيقية كثيرة وإيمان بوجود إله خلق كل شيء بقدر.

ولقد دفع إخفاق نظرية التحقق في المعنى بعض الفلاسفة إلى البحث عن نظرية ملائمة لطبيعة اللغة وتنوع المفاهيم والأفكار، وانتهوا من ذلك إلى القول بنظرية الاستعمال في المعنى التي دافع عنها فتجنشتين في أطروحته الأخيرة وفلاسفة مدرسة أكسفورد. وتعتمد هذه النظرية على افتراض مؤداه أن معنى الكلمة (أو التعبير) هو الاستعمال في اللغة؛ يقول فتجنشتين: "فيما يتعلق بطائفة (كبيرة) من الحالات -وليس جميعها- التي تستعمل فيه كلمة "معنى" يمكن تحديدها هكذا: معنى الكلمة هو استعمالها في اللغة". 28 وقد خلص فلاسفة الوضعية المنطقية من تحليلهم المنطقي للغة إلى أن اللغة تقوم بوظيفتين أساسيتين هما: الوظيفة المعرفية (cognitive)، وتقوم فيها اللغة بوصف الواقع، وتتجلى في العبارات التركيبية التي تغيدُ خبراً عن الواقع يمتمل الصدق أو الكذب، والوظيفة غير المعرفية (non- cognitive) وتندرج تحتها عبارات الأخلاق والجمال من جهة والعبارات الميتافيزيقية من جهة أخرى. وذهب الوضعيون المنطقيون إلى أن الوظيفة الوحيدة الجديرة باهتمام البحث الفلسفي هي الوصف أو التقرير. ولكن فلاسفة أكسفورد أثبتوا خطأ هذا الرأي على أساس أن النظر إلى اللغة ووظيفتها على هذا النحو يمثل ما أسماه أوستن بالمغالطة الوصفية (descriptive fallacy)، 29 لأننا لو قبلنا وجهة نظر الوضعية المنطقية، فماذا نفعل بالعبارات الأخرى التي لا تصف الواقع مثل جمل الأمر والنهي والاستفهام وجمل الميتافيزيقا؟ وهل يمكن الحكم عليها بأها خالية من المعنى؟ إن جل كتابات فلاسفة أكسفورد، على الرغم من تنوع المجالات التي تعالجها، تمثل محاولة للكشف عن المغالطة الوصفية وبيان النتائج المترتبة عليها ومحاولة تجاوزها. وقد انتهى هؤلاء الفلاسفة

Burtt, E. A.: The Metaphysical Foundations of Modern Physical Science (London, 1964), P. 58.

وانظر في ذلك أيضاً: روبرت م. اغروس وجورج ن. ستانسيو: العلم في منظوره الجديد، ترجمة كمال خلايلي (الكويت: سلسلة عارم

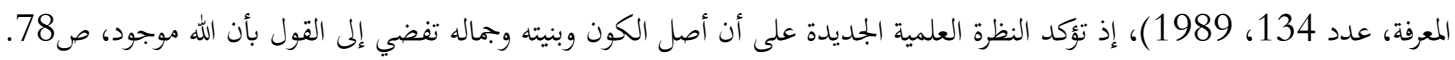
Wittgenstein, L.: Philosphical Investigations, trans. By G. E. M. anscombe

(Oxford: Basil Balckwell, 1963), part 1, sec. 43, p20. Austin, J. L.: How to do things with Words, edited by J. Jo. Urmson (New York: 
إلى الاعتراف بوظائف متباينة للغة لا يزيد الوصف على أن يكون واحدة منها، وكشفوا بذلك عن أنماط مختلفة من التعبير، وذهبوا إلى أن كل نمط له منطقه الخاص الذي يكسبه شرعيته ومعناه ووظيفته اللغوية والمعرفية.

وإذا كان معنى الكلمة أو العبارة يتحدد باستعماها في اللغة، فيجب أن يكون هذا الاستعمال محكوماً بقواعد بحيث يجعل الكلمة أو العبارة ذات مغزى، ومن ثم تأتي ضرورة التفرقة بين الاستعمال الصحيح والاستعمال غير الصحيح. فالاستعمال الصحيح هو الذي يجيء منسجماً مع القواعد التي تضبطه، أما الاستعمال غير الصحيح فهو الذي لا يخضع لتلك القواعد ولا يتقيد بها. ومن هنا راح أصحاب نظرية الاستعمال في المعنى يبحثون عن قواعد استعمال الكلمات والعبارات، ويتجلى هذا في بحث أوستن عن القواعد التي تحكم العبارات الأدائية مثل "إني أهب وأورّث ساعتي لأخي". 30 وطور كثير من أتباع أوستن هذه الفكرة مثل ألستون الذي ذهب إلى أن هناك قبولاً واسع النطاق لوجهة النظر القائلة بأن المعنى اللغوي هو مسألة قواعد، وإن شئت أن تضع ذلك بصورة أكثر وضوحاً فقل إن الحقيقة القائلة بأن التعبير اللغوي له معنى معين هو الحقيقة القائلة بأن استخدامه محكوم بقواعد معينة. 31

لقد ترتب على نظرية الاستعمال في المعنى عدة نتائج مهمة من أبرزها القول بأن كل نمط من أنماط القضايا له نوع خاص من المعنى، وعلى هذا النحو رد فلاسفة أكسفورد الشرعية إلى مفاهيم الميتافيزيقا والأخلاق والجمال بعد أن سلبها إياها فلاسفة الوضعية المنطقية بحجة أها زائفة ولا تقبل التحقق الحالي أو المقبل. ويترتب على هذا أيضاً أن مفاهيم العلوم التجريبية ليست وحدها المفاهيم الحقيقية وما عداها مفاهيم زائفة، وإنما مفاهيم الدين والأخلاق والعلوم الإنسانية بعامة هي أيضاً مفاهيم حقيقية. وهذا يدفعنا إلى البحث عن معايير أخرى غير التحقق التجريبي للفصل بن المفاهيم الحقيقية والزائفة مثل قدرة المفهوم على التفسير والتحليل والتنبؤ فضلاً عن بساطته.

30 3 303 اظر هذه القواعد في: صلاح إسماعيل: التحليل اللغوي عند مدرسة أكسفورد (بيروت: دار التنوير للطباعة والنشر، الطبعة الأولى، 1993)، ص142-143

Alston, W. P., "Semantic Rules", in Semantics and Philosophy, edited by M. K. Munitz and P. K. Unger (New York: New York University Press, 1974), P. 17. 
وتتمتع نظرية الاستعمال بمزايا، أبرزها أها تتفادى الصعوبات التي تواجه نظرية التحقق وغيرها من نظريات المعنى. فنظرية التحقق ترتكز على النظرية الإشارية، وبذلك تواجه صعوبة وجود رموز ذات معنى دون أن تكون ذات (ما صِدُق) مثل العدالة والشجاعة والكرم وما جرى مجراها، ووجود رموز ذات (ما صدق) واحد على الرغم من عدم ترادفها في المعنى مثل "مخلوق بقلب" و"خخلوق بكليتين" وتفسر نظرية

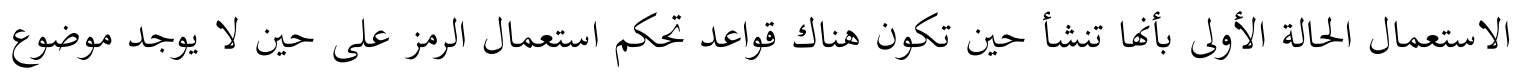
يصدق عليه ذلك الرمز، أما الحالة الثانية فتنشأ حين تكون هناك قواعد مختلفة لكل رمز تحدد الموضوع الذي يشير إليه الرمز أو يصدق عليه، على حين يكون الموضوع الذي يتم تحديده في هذه الحالة شيئاً واحداً في الواقع.

ولقد فطن البلاغيون المسلمون، فضلاً عن الأصوليين، إلى نظرية الاستعمال أو السياق وتحديداً سياق الموقف عندما قالوا: "لكل مقام مقال". والحق أن توضيح المعنى على المستوى الوظيفي (الصوتي والصريف والنحوي) وعلى المستوى المعجمي (العلاقات العرفية بين المفردات ومعانيها) لا يقدم لنا إلا "معنى المقال"، أو "المعنى الحريف" كما يسميه النقاد، أو "معنى ظاهر النص" كما يسميه الأصوليون. 32 وإذا شئنا أن نقدم المعنى في صورته الكاملة إلى حد ما، فلا بد من أن نضيف إلى "المعنى المقالي" جانباً آخر هو "المعنى المقامي" وهو ظروف أداء المقال ويسمَّى مقاماً.

أما وقد عرضنا لأهم الآراء في مشكلة المعنى وأثرها في التعامل مع المفاهيم والحكم عليها بأها مفاهيم حقيقية أو زائفة، وكذلك وصفها بأها واضحة أو غامضة، فقد بقي علينا أن نشير إلى أخطر الأمراض الدلالية التي تصيب المفاهيم، ألا وهو "تحريف المعنى". يجب أن نميز بين ظاهتين دلاليتين هما "تغيير المعنى" و "تحريف المعنى". ولقد حاول علماء اللغة رصد الأسباب التي تؤدي إلى تغيير المعنى، ومن أهم تلك الأسباب ما يلي:

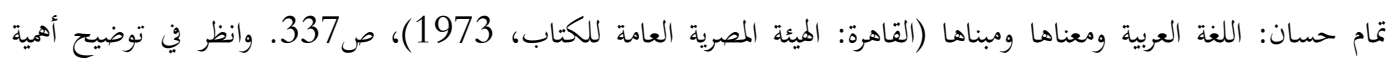

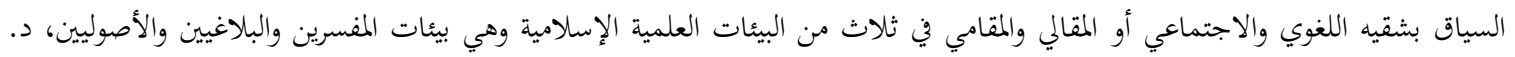

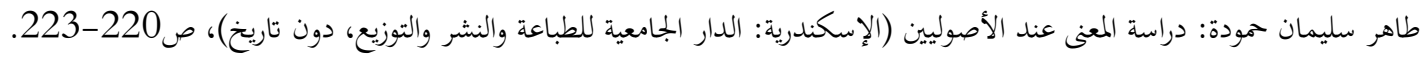


1- ظهور الحاجات الجديدة: يلجأ أصحاب اللغة إلى الكلمات القديمة التي توارت معانيها فيحيون بعضها ويطلقوها على المخترعات الحديثة. وفي هذه الحالة نستعمل كلمات قديمة لمعان جديدة فيحدث تغيير في المعنى ومن أبرز الأمثلة على ذلك كلمات المدفع والدبابة والسيارة والقاطرة والثلاجة والسخان والمذياع والجرائد والصحف وهلم جرا. 33 ولعلنا نلاحظ أن الاكتشافات العلمية تمثل الكثرة الغالبة من الحاجات الجديدة التي تؤدي إلى تغيير المعنى.

2- العوامل النفسية والاجتماعية: هناك سبب آخر لتغيير المعنى هو الحظر أو التحريم، إذ تمنع اللغات استعمال بعض الكلمات ذات الدلالات البغيضة أو التي توحي بشيء مكروه، ولذلك تستبعدها وتستخدم بدلاً منها كلمات أخرى، وتدخل الكلمة المستبعدة في إطار كلمات "اللامِسَاس" على حين توصف الكلمة المفضلة بأها من كلمات التلطف. وإذا كان "اللامساس" يؤدي إلى التلطف في التعبير، فإن التلطف يؤدي هو الآخر إلى تغيير المعنى. ومن أمثلة ذلك أننا لا نكاد نسمع كلمة "مرحاض" أو "كنيف"، وإنما نسمع بدلاً منها كلمة دورة المياه أو "التواليت"، وكذلك لا نكاد نسمع كلمة "حبلى" وإنما نسمع كلمة "حامل". ويترتب على تغيير المعنى تغيير المفاهيم نظراً لأن المفاهيم التي نعبر عنها بألفاظ أو مصطلحات هي في جوهرها معان مجردة. ولكن عملية تغيير المعنى على هذا النحو تعد عملية طبيعية ولا غبار عليها، وإنما الشيء الذي يتعين علينا الانتباه إليه هو "تحريف المعنى"، وهو أمر مغاير "لتغيير المعنى"، ذلك أن تغيير المعنى يتم بصورة طبيعية إلى حد كبير، يجظى بقبول عند الجماعات اللغوية والمجامع اللغوية والهيئات العلمية. أما تحريف المعنى فيحدث تحقيقاً لمقاصد معينة ولأغراض فكرية ومعرفية عند من يمارسه. خذ مثلاً مفهوم "العقل" بحد أن الابحاهات المادية في العلم والفلسفة، التي تفسر الأشياء بلغة المادة وحدها، تذهب إلى أن خير طريقة للبحث في العقل هي إظهار كيفية انبثاق العقل من المادة. وتبعاً لذلك لا يزيد العقل على أن يكون عضواً مادياً. ولكن أروع ما قدمه القرن العشرون هو هدم النظرية المادية في العقل، وقد جاء ذلك على يد ويلدر بنفيلد Penfield في كتابه لغز العقل الذي يقول فيه: "يبدو لي من المؤكد أن تفسير العقل على أساس 
النشاط العصبي داخل المخ سيكون دائماً تفسيراً مستحيلاً تمام الاستحالة". 34 والنتيجة التي يخلص إليها بنفيلد وتتجلى في غير موضع من أعماله هي قوله: "يبدو لي أنه من المعقول تماماً أن أقترح، كما اقترحت في

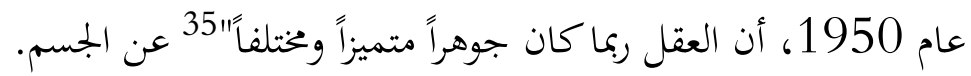

وهذا التصور الأخير ينسجم مع الفهم الصحيح لدلالة مفهوم العقل. فالعقل جوهر روحاني خلقه الله تعالى متعلقاً ببدن الإنسان، وإن شئ قل: إنه نور في القلب يعرف به الإنسان الحق والباطل. وفي الاتحاهات العلمانية المعاصرة نجد تحريفاً آخر لمعنى العقل، إذ يرى أنصار هذه الاتحاهات أن العقل هو الإمام الأوحد الذي يهدي الإنسان إلى المعرفة، والذي يحدد له الحق والباطل والخير والشر. وطالما أن العقل البشري قد بلغ مرحلة كبيرة من النضج فلا حاجة بنا إلى الوحي، لأنه لا سلطان على العقل إلا العقل نفسه. وإذا كانت الاتجاهات المادية في العلم والفلسفة قد حرفت معنى مفهوم العقل من زاوية الوظيفة التي يؤديها، فالعقل ملكة لدى إنسان محدود الإدراك. والمغالطة هنا هي مغالطة سحب الجز على الكل، وهي تدخل في باب توسيع المعنى أيضاً. ولكن التصور الإسلامي للمعرفة يرى أن العقل لا يزيد على أن يكون وسيلة من وسائل الإدراك، وأن كل وسائل الإدراك لدى الإنسان تقع في باب الوجود، وأن هناك مصدراً آخر من مصادر المعرفة هو الوحي، وأنه لا تعارض بين العقل والوحي في الإسلام، بل الصواب أن هناك تكاملاً بينهما. فالعقل من خلق الله، وهو هبة الله للإنسان ليدرك به ما وسعه الإدراك، والوحي من لدن الخلاق العظيم ليهدي الإنسان كله وعقله على وجه الخصوص. يتضح مما أسلفناه أن هناك بعض القواعد الدلالية التي تحكم التعامل الصحيح والدقيق مع المفاهيم،

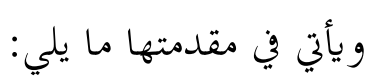
1- الاعتراف بالخصوصية الحضارية والسمات اللغوية والمنطقية للغة التي تصاغ فيها المفاهيم.

Penfield, W.: The Mystery of the Mind (Prineceton, New Jersey: Princeton 
2- معرفة المعنى اللغوي والمعنى الاصطلاحي للألفاظ التي تعبر عن المفاهيم، ولا تساعد معرفة هذه المعاني في الكشف عن الدلالات المتنوعة للمفهوم في حالة التعامل العادي الذي يبغي البحث عن الحقيقة فحسب، وإنما تساعد أيضاً في الكشف عن عمليات الثلبيس والتحريف الدلالي التي قد يتعرض لها المفهوم موضوع البحث. 3- - معرفة السيرورة الدلالية للمفهوم، والتمييز بين الدلالات الأصلية التي بتلت عند وضعه أولَ مرة، والدلالات التاريخية التي اكتسبها عبر تطوره. 4- يليل البنية الدلالية للمفاهيم والتمييز بين العناصر الأساسية والعناصر الفرعية في هذه البنية، وهذا التمييز يساعد على إدراك الفرق بين التطور الدلالي الطبيعي وتريف دلالة المفهوم سواءٌ عن طريق التضييق أو التوسيع أو بأية صورة أخرى. 5- في حالة ترجمة المفاهيم بجب على المترجم معرفة الدلالات الأصلية والتاريخية للمفهوم الذي ينقله إلى اللغة العربية، مثلاً، ويجب أيضاً أن يكون على وعي بأصول العربية حتى يختار مقابلاً دقيقاً للمفهوم الأجنبي. وفي حالة الإخلال بأي شرط من هذين الشرطين يحدث الخطأ الدلالي في الترجمة، ناهيك عن اللاتحديد في الترجمة الذي يحدث نتيجة لاختلاف الخصائص اللغوية والثقافية أما إذا كان المترجم يفي هذذين الشرطين تمام الوفاء بيد أنه يحرف الترجمة عن عمد فذلك شأن آخر. ويجب على أصحاب الفكر إظهار هذا التحريف الدلالي والتنبيه عليه، لأن المفهوم الذي حرفت دلالته يفسد بقية المفاهيم في النسق المعريف كما تفسد الثمرة المعطوبة ما حولها من ثمرات صحاح. 